\title{
Use of semi-interpenetrating polymer network in fiber- reinforced dental composites
}

\author{
Aftab Ahmed Khan* \\ Dental Biomaterials Research Chair, College of Applied Medical Sciences, King Saud University, Riyadh; Saudi Arabia
}

Over the time, composite resins have evolved from bisphenol A glycidyl methacrylate (bis-GMA) monomer developed by Bowen in 1962 to fiber-reinforced composite (FRC) substructures. The 54 years of endless refinement along this path has virtually changed the original composition of this extraordinary material [1]. Over the years, many studies such as changing the matrix, filler type, size and shape, have been conducted to improve the mechanical properties of the dental composite materials [2].

With the development of FRC, a new era of metal-free, adhesive and esthetic dentistry has been introduced [3]. The key factors that influence the physical properties of FRC are fiber loading in a matrix system, fiber orientation, fiber position and above all efficacy of the bond at the fiber-matrix interface [4]. However, if the reinforced polymer does not wet the surface of every fiber present in FRC, the physical and mechanical properties such as solubility, sorption, modulus and flexural strength are affected due to voids $[5,6]$.

The recent advent of FRC material having silanted glass fibres impregnated with an interpenetrating polymer network (IPN) resin matrix has gained investigators' interest. In IPN, or more precisely semi-IPN matrix, linear and cross-linked polymers phases are not chemically bonded together [7]. The key and decisive property of semi-IPN is independency of polymeric network [8]. The linear and cross-linked polymer networks coexist in the same volume of the space $[9,10]$. In short, their bonding to composite resin and to adhesives/ composite cements rely on interdiffusion bonding mechanism [11, 12]. On the surface of FRC with semi-IPN, the enriched layer of linear polymer phase is present [11].

The IPN bonding mechanism is already established in repairing the denture and bonding of acrylic teeth to the denture base polymers [13]. However, their use in FRC is recent. Development of the FRC with new types of resins systems can led to the use of FRCs in a variety of dental disciplines. It is envisaged that if a suitable adhesive resin is allowed to diffuse into linear polymer phase on the surface of the FRC, the final quality of FRC might be improved further, and desirable mechanical and physical properties might be achieved.

\section{References}

1. Ferracane JL (2011) Resin composite--state of the art. Dent Mater 27: 29-38. [Crossref]

2. Garoushi S, Vallittu PK, Watts DC, Lassila LV (2008) Polymerization shrinkage of experimental short glass ?ber-reinforced composite with semi-inter penetrating polymer network matrix. Dent Mater. 24:211-5.

3. AlJehani YA, Baskaradoss JK, Geevarghese A, AlShehry MA, Vallittu PK (2016) Shear Bond Strength between Fiber-Reinforced Composite and Veneering Resin Composites with Various Adhesive Resin Systems. J Prosthodont. 25:392-40. [Crossref]

4. Butterworth C, Ellakwa AE, Shortall A (2003) Fibre-reinforced composites in restorative dentistry. Dent Update 30: 300-306. [Crossref]

5. Garoushi S, Vallittu PK, Lassila LV (2007) Use of short fiber-reinforced composite with semi-interpenetrating polymer network matrix in fixed partial dentures. $J$ Dent. 35:403-8. [Crossref]

6. Lastumäki TM, Lassila LV, Vallittu PK (2003) The semi-interpenetrating polymer network matrix of fiber-reinforced composite and its effect on the surface adhesive properties. J Mater Sci Mater Med. 14:803-9. [Crossref]

7. Sperling LH (2012) Interpenetrating polymer networks and related materials. Springer Science \& Business Media.

8. Vallittu PK (2009) Interpenetrating polymer networks (IPNs) in dental polymers and composites. J Adhes Sci Tech. 23:961-72.

9. Winkler S, Monasky GE, Kwok J (1992) Laboratory wear investigation of resin posterior denture teeth. J Prosthet Dent 67: 812-814. [Crossref]

10. Reis KR, Bonfante G, Pegoraro LF, Conti PC, Oliveira PC, et al. (2008) In vitro wear resistance of three types of polymethyl methacrylate denture teeth. J Appl Oral Sci 16: 176-180. [Crossref]

11. Mannocci F, Sherriff M, Watson TF, Vallittu PK (2005) Penetration of bonding resins into fibre-reinforced composite posts: a confocal microscopic study. Int Endod J. 38:46-51. [Crossref]
Copyright: (C)2017 Khan AA. This is an open-access article distributed under the terms of the Creative Commons Attribution License, which permits unrestricted use, distribution, and reproduction in any medium, provided the original author and source are credited.
Correspondence to: Aftab Ahmed Khan, Dental Biomaterials Research Chair, College of Applied Medical Sciences, King Saud University, Riyadh, Saudi Arabia, E-mail: aakjk@hotmail.com

Received: October 28, 2017; Accepted: November 13, 2017; Published: November 15, 2017 